International Journal of English Literature and Social Sciences
Vol-6, Issue-1; Jan-Feb, 2021

\title{
A Study of Literary Devices used in the Posts on
}

\section{Instagram}

\author{
Bageshree Ramdas Bageshwar
}

Received: 13 Oct 2020; Received in revised form: 10 Jan 2021; Accepted: 03 Feb 2021; Available online: 27 Feb 2021

(C)2021 The Author(s). Published by Infogain Publication. This is an open access article under the CC BY license

(https://creativecommons.org/licenses/by/4.0/).

\begin{abstract}
Reading plays an important role in human life. Good literature offers food for the soul. A few years back, the relaxed life style of people allowed them to read a lot in their free time. But, the hectic pace of today's 24-hour lifestyle does not allow people to make time for reading books. So, the question arises how the purpose of 'brain food' rather 'life food', which was previously served by books is now served. The answer may lie in the increasing number of people active on social media. This research paper deals with the study of posts shared on Instagram. These posts are studied linguistically and variations of normal forms of language are found. Various techniques or ways of the presentation of matter in these posts is also one of the topics of study. The researcher has tried to explore how oxymoron, pun, repetition, wordplay, metaphors etc. are used to create special effects in the posts. Different types of posts are studied in order to study different factors. With the help of this study, the researcher has tried to find out whether these posts are serving the purpose of literature to some extent in human life.
\end{abstract}

Keywords-Instagram, Language, Literary, Pun, Wordplay.

\section{INTRODUCTION}

Literature is universal to all people, all places, and all times. Literature knows no barriers, neither culture, age, gender, nor religion. It delights the mind, and the soul. It satisfies our craving for beauty and knowledge through the power of its language. But, literature conveys more than mere pleasure. It also communicates meaning. Good literature offers food for the soul. It is valued for what it reveals about our inner selves and outer lives. It interprets our hidden emotions and gives them a voice.

Literature has always played an important role in human life. One's life is very short and so one cannot have all types of experiences in it. But, literature helps one to know a lot of things in this short time. As a result, literature is not something special or set apart from our daily lives. Rather, it is an integral part of everyone.

A few years back, people used to lead a relaxed life. They had enough time to read books. They could enjoy literature fully. But, in the present time, the life has become very fast. The hectic pace of today's 24-hour lifestyle does not allow one to make time for reading books. People are pulling back-to-back shifts in the I.C.U. or commuting by bus to three minimum wage jobs. They are not just busy, but tired, exhausted, dead on their feet. The Marathi saying 'Wachal tar Wachal' needs to be read and meant the other way round in this condition.

Now, the question arises, how the purpose of 'brain food' rather 'life food', which was previously served by books, is now served. The answer may lie in the increasing number of people active on social media; reading, sharing the verbal posts on it. This research paper deals with the study of such popular posts on Instagram and the role of language used in them. It includes the study of variations of normal forms of language and the ways of presenting matter in these posts; which make them popular and successful. With the help of this study, the researcher has tried to find out whether these posts are serving the purpose of literature to some extent in human life.

\section{AIM}

To study the variations of normal forms of language and various ways of presenting matter in the posts on Instagram, which make them popular. 


\section{OBJECTIVES:}

1) To collect posts from Instagram.

2) To study these posts linguistically and find out variations of normal forms of language.

3) To find out various techniques or ways of the presentation of matter in these post and categorising the posts accordingly.

4) To study this variation and the factors responsible for it with the help of examples.

5) To analyze the data and draw conclusion.

\section{DATA \& ANALYSIS:}

Data is collected from the posts shared on Instagram. Various types of posts are collected in order to find and study different features.

\subsection{Factors responsible for variation in normal form of} language used in posts on Instagram:

\subsubsection{Oxymoron:}

gentlemensmafia $\cdot$ Following

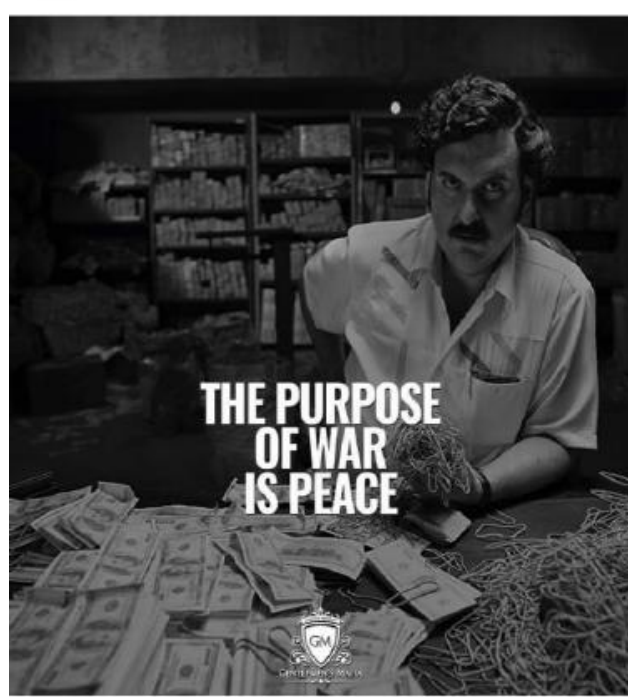

$\circ \bigcirc \nabla$

11,938 likes
Fig.1: Examples of Instagram posts showing Oxymoron therealkushaltandon • Following

Better

an oops

than a

what if.

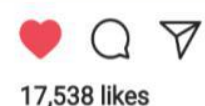

Two opposite ideas in the same sentence (Oxymoron) An oxymoron is a rhetorical device that uses an ostensible self-contradiction to illustrate a rhetorical point or to reveal a paradox. ("Oxymoron," 2021). Oxymoron is used to create some sort of drama for the reader or listener, and sometimes they are used to make the person stop and think, whether it is to laugh or to ponder.E.g. 'Sometimes it is better to lose to get a taste of what it means to win.' In this example, two contradictory ideas i.e. losing and winning are used in the same sentence. Through the use of Oxymoron, a positive energy is released by which motivation is served. The positive attitude towards failure is encouraged through this.

Some more such examples:

a) Don't be afraid of bad roads, they make you a good driver.

b) The butterflies in my stomach are turning into fire breathing dragons.

c) Failure is an orphan waiting to be adopted by accomplishment.

d) Dear stars, fall in love with darkness. It can give you a chance to shine bright.

e) Throw open the windows for fresh breeze without being blown away. 
4.1.2. Pun:

punsworld · Following

Boss: "How good are you at PowerPoint?" Me: " I Excel at it."

Boss: "Was that a Microsoft Office pun?" Me: "Word."
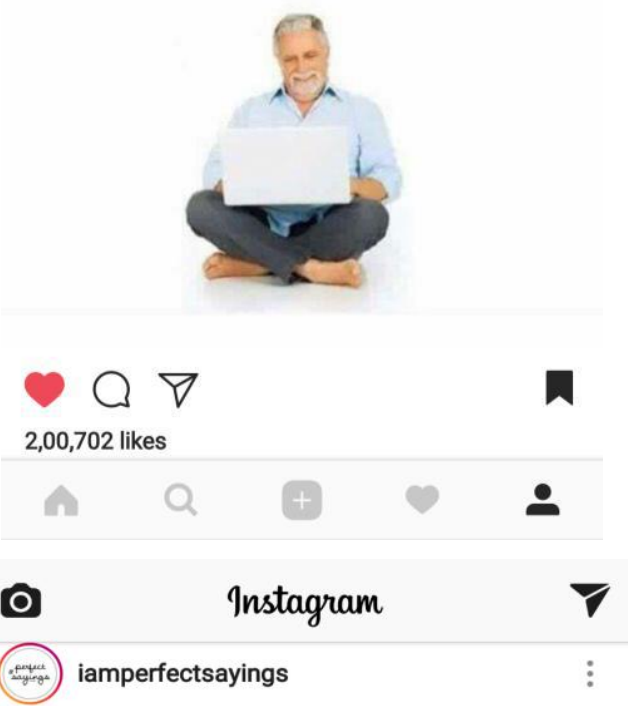

eyelashes are supposed to prevent things from going into your eyes but whenever i have something in my eye it's always an eyelash.

eyeronic

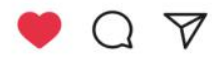

Liked by cutenessuitsme and 1,27,396 others

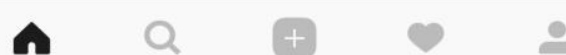

Fig.2: Examples of Instagram posts showing Pun

Pun denotes a play on words that are either identical in sound (homonyms) or very similar in sound but are sharply diverse in significance. (Abrams, 2015).E.g. 'Make peace with your broken pieces.'In this example, pun is used to make a meaningful sentence that may help to bring a person out of depression.

Some more examples: a) I am on a Seafood diet. Every time I see food, I eat it.

b) I'm going to stand outside, so if anyone asks, I'm outstanding.

c) If you are taller than your mom, you should call her a minimum.

d) Taking notes, but can they carry a tune?

e) Cheers to the world being made Beerable.

\subsubsection{Repetition:}

$\Xi$ quotes_n_much_more $\cdot$ Following

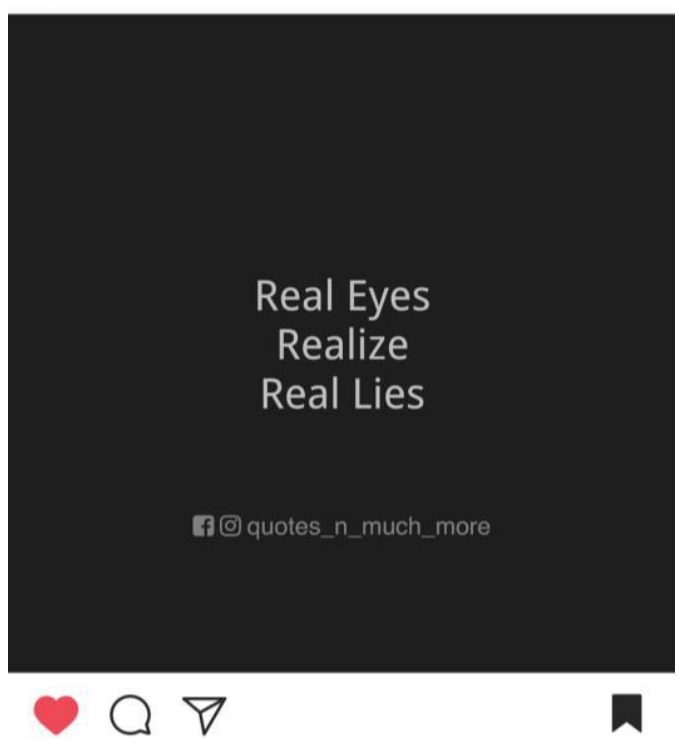

18,445 likes

motivationmafia $\cdot$ Following
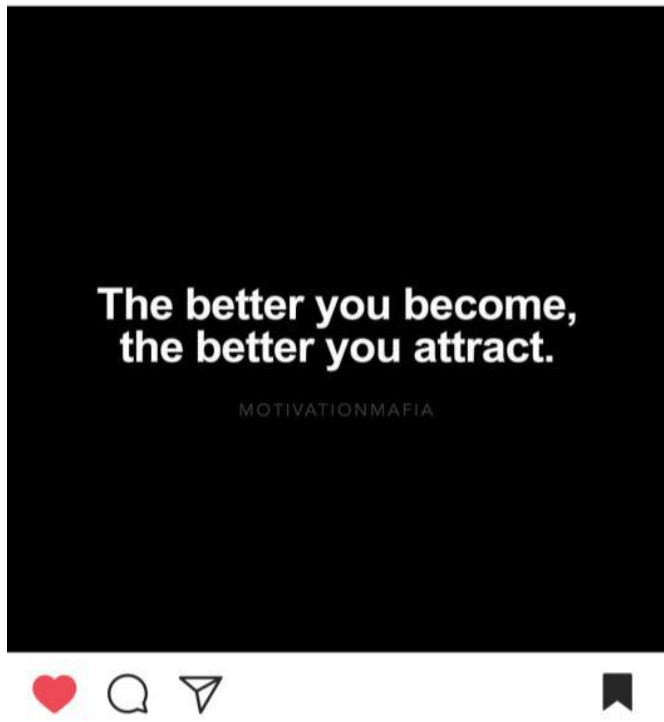

17,983 likes

Fig.3: Examples of Instagram posts showing Repetition 
Repetition of some letters and words - In some of the posts, certain letters or words are used more than once. This may create humour sometimes or it can be used to emphasize a particular point.E.g. 'If you clean a vacuum cleaner you are a vacuum cleaner.'This example creates humour.

More examples:

a) The best revenge is no revenge. Move on. Be happy.

b) How you see the world is the world you create for yourself.

c) Real Eyes Realize Real Lies.

d) The better you become, the better you attract.

e) The two things a journey teaches us - Let go and Let's go.

\subsubsection{Wordplay, Witticism, Blend:}

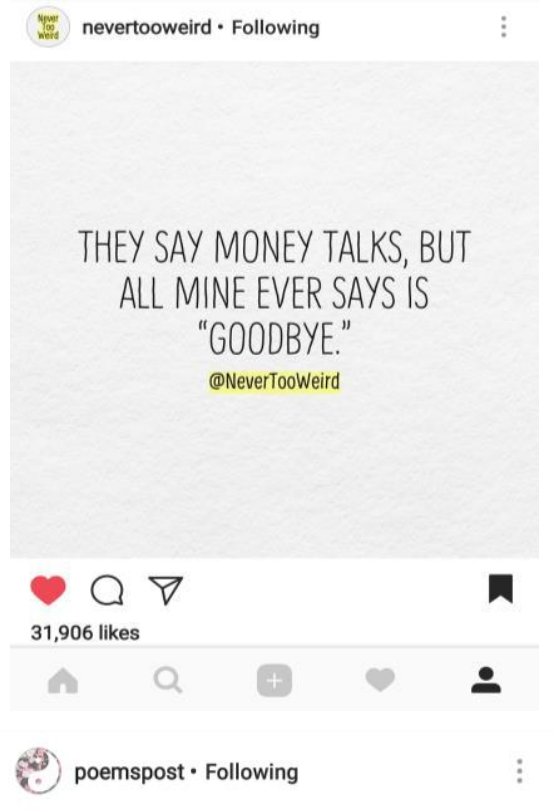

"This may be a sad chapter but you are not a sad story"

- a follower told me this, thank you. (May 4th)

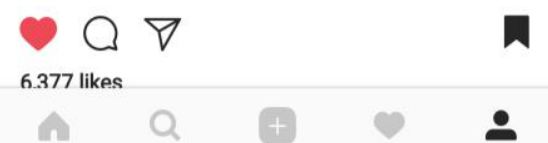

Fig.4: Examples of Instagram posts showing Wordplay, Witticism, Blend
Wordplay, Witticism, Blend - Some of the posts use wordplay, witty language or blend in order to create humour, entertainment, etc. It may also provide brain food. E.g. ' Don't text me back with 'K', I am so much more than just Potassium.' This example shows witticism, creating humour.

More examples:

a) Nothing in my life ever works out, so why should I?

b) Don't waste your thunder on things that run for shelter in rains.

c) I need a constant dose of change.

d) How do you make a Holy water? You boil the Hell out of it.

e) Wish I had a friend like me.

\subsubsection{Metaphors:}
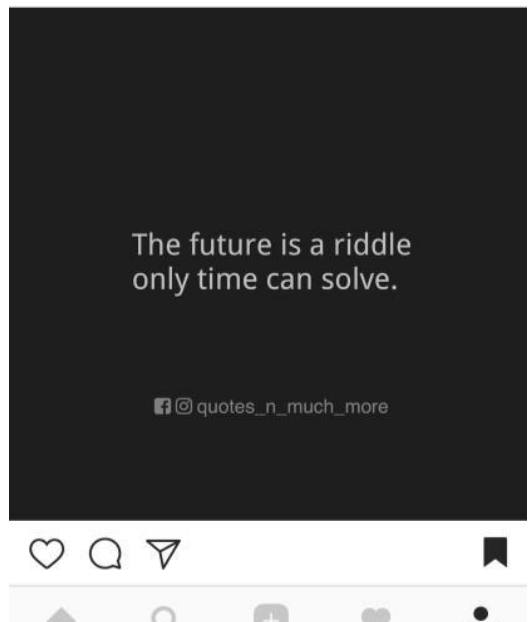

quotes_n_much_more $\cdot$ Following

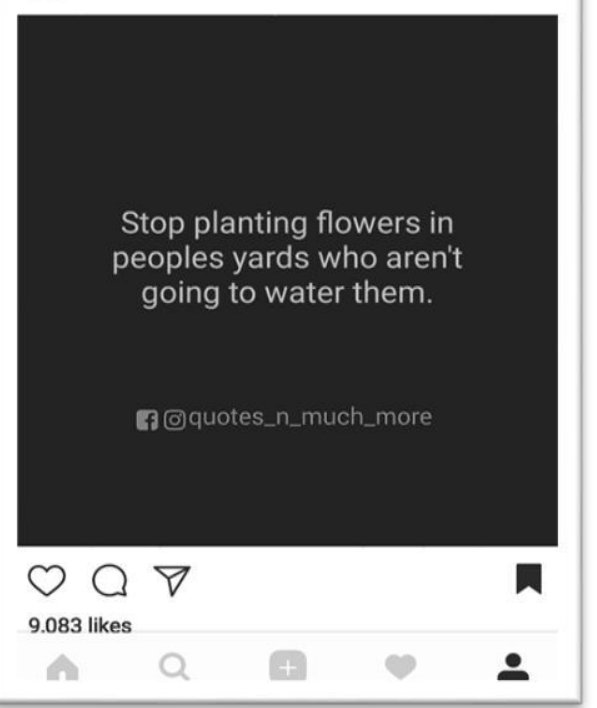

Fig.5: Examples of Instagram posts showing Metaphor 
Metaphors - Some posts use metaphors to present their content effectively. In a metaphor, a word or expression that in literal usage denotes one kind of thing is applied to a distinctly different kind of thing, without asserting a comparison. These metaphorical sayings often have some hidden meanings apart from the superficial meanings.

E.g.'The future is a riddle only time can solve', here, future is called a riddle, attributing all the qualities of a riddle to it. This makes the concept of future clearer.

More examples:

a) The world is a book and those who don't travel only read one page.

b) Sometimes you need to burn bridges to stop yourself from crossing them again.

c) A ship is always safe at shore but that is not what it's built for.

d) Stop planting flowers in people's yards who aren't going to water them.

e) We can't direct the wind but we can adjust the sails.

\subsubsection{Questions:}

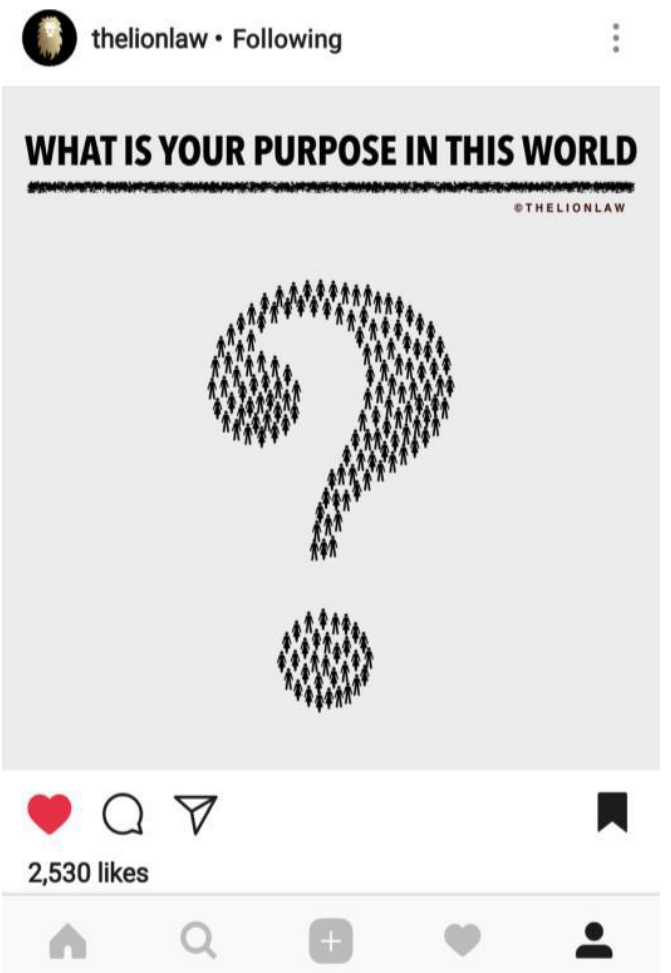

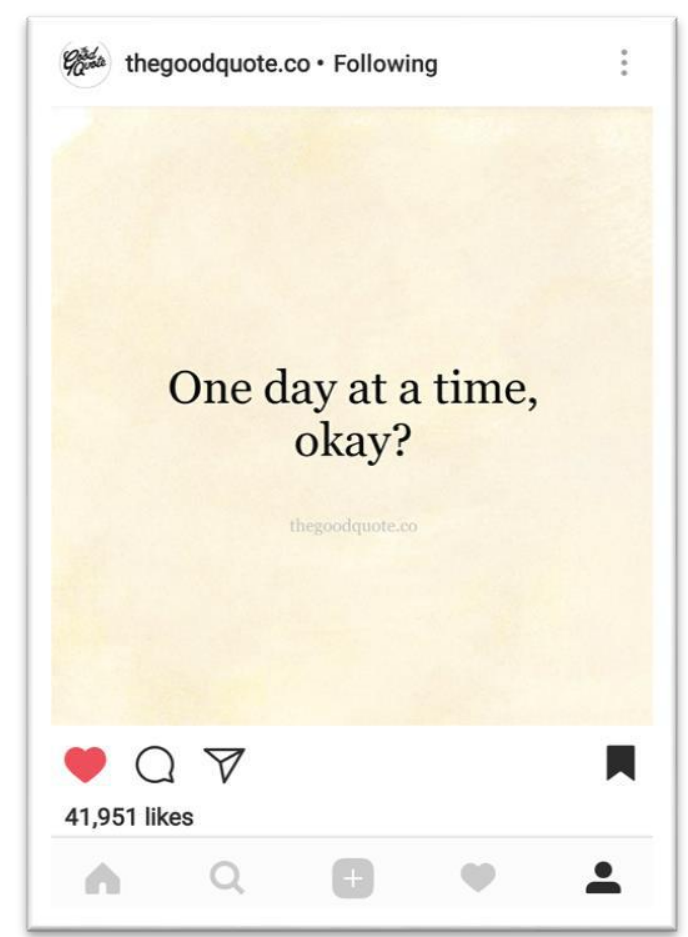

Fig.6: Examples of Instagram posts showing Questions

Questions - In some of the posts, only one question is asked. The question is such, which one needs to ask to oneself. One needs to find out the answers oneself. These questions start the thinking process and also make people realize what's happening in their lives. They may also show direction of their life to them.

E.g. a) What is your purpose in this world?

b) What does success mean to you?

c) What is your true potential?

d) When will you live the life you're meant to live?

e) Who will you believe? Yourself or other people's opinion. 


\subsubsection{Lines -1 Thought:}

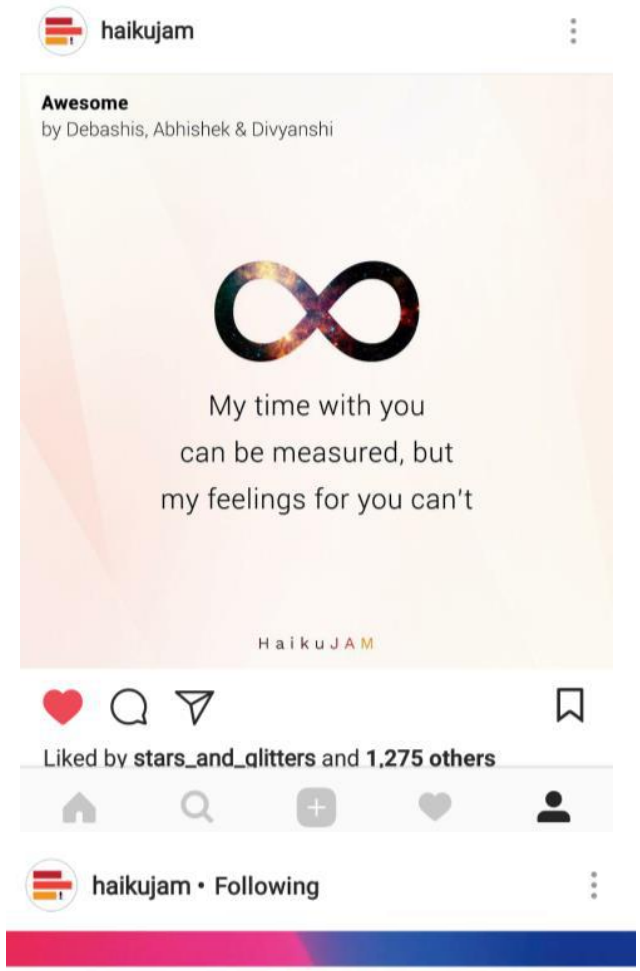

iPhone X:

Sorry liver, you

are too damaged

to get me an iPhone.
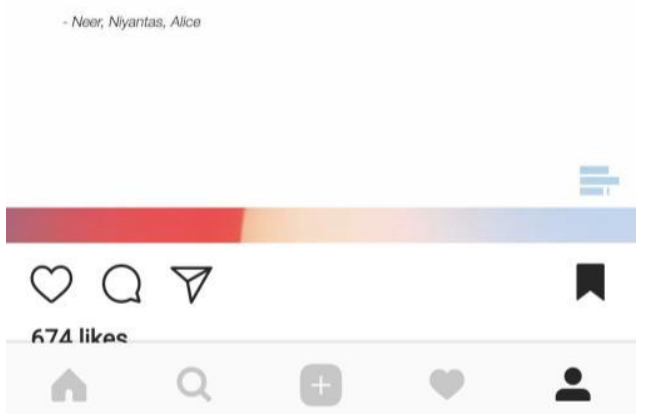

Fig.7: Examples of Instagram posts showing 3 Lines- 1 Thought

3 Lines-1 Thought - In some posts, three lines are used to express one thought. It gives a short explanation. The thought is related to human life and is often interpreted appropriately by using three short lines.

E.g. Time to Play: 'The subtle game of life, without an instruction manual.'

The harsh reality of life is expressed in these 3 lines.
More examples:

a) Innocence: 'He kept blaming the network service provider for his unseen messages.'

b) Tired: 'I'm tired of people's fakeness because sometimes I feel they are infectious.'

4.1.8.
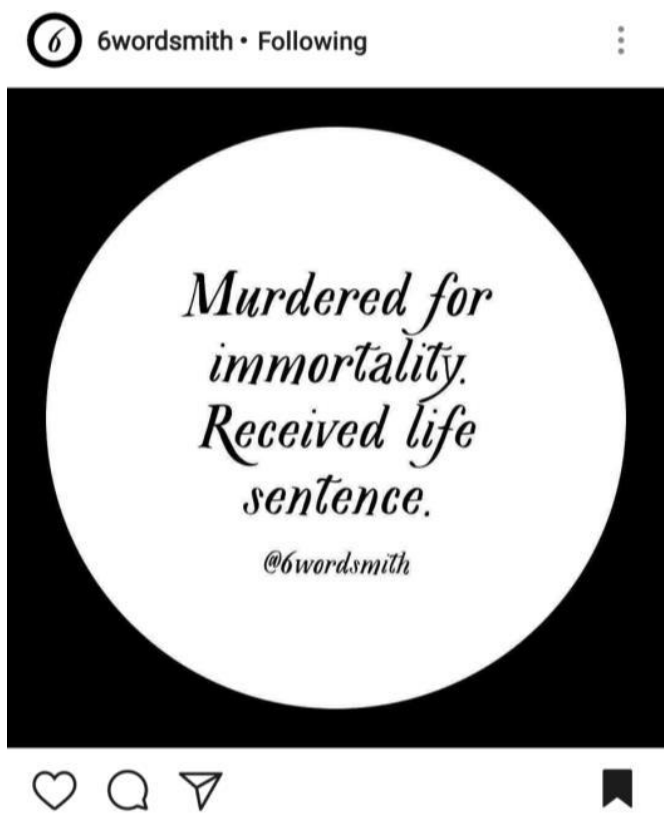

6,398 likes
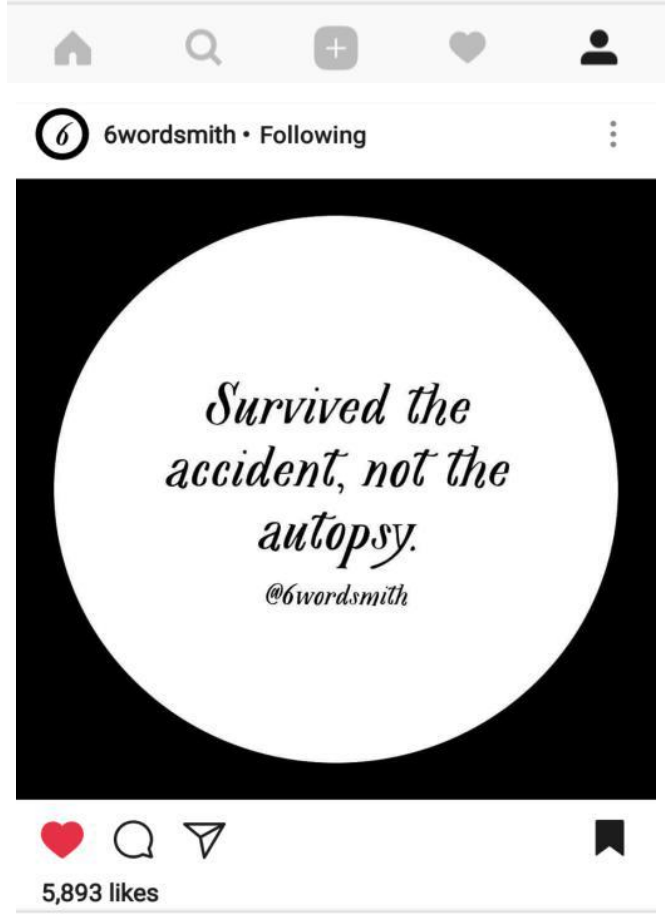

Fig.8: Examples of Instagram posts showing 6 Words Story 
6 Words Story: In some of the posts, using only six words a story is created. These six words are chosen very wisely and their arrangement is such that they create a story expressing truths about life.

E.g. ' The ambulance slowed, the urgency gone.'This example tells the harsh reality of life-death situation.

More examples:

a) Murdered for immortality. Received life sentence.

b) Survived the accident, not the autopsy.

c) Please drive safe. Delivered, not read.

d) Bottle is empty. So was he.

e) Awake, screaming, paralysed. Unnoticed. Surgery begins.

\subsubsection{Short Conversations:}

iamperfectsayings · Following

Society: be yourself

Society: not like that

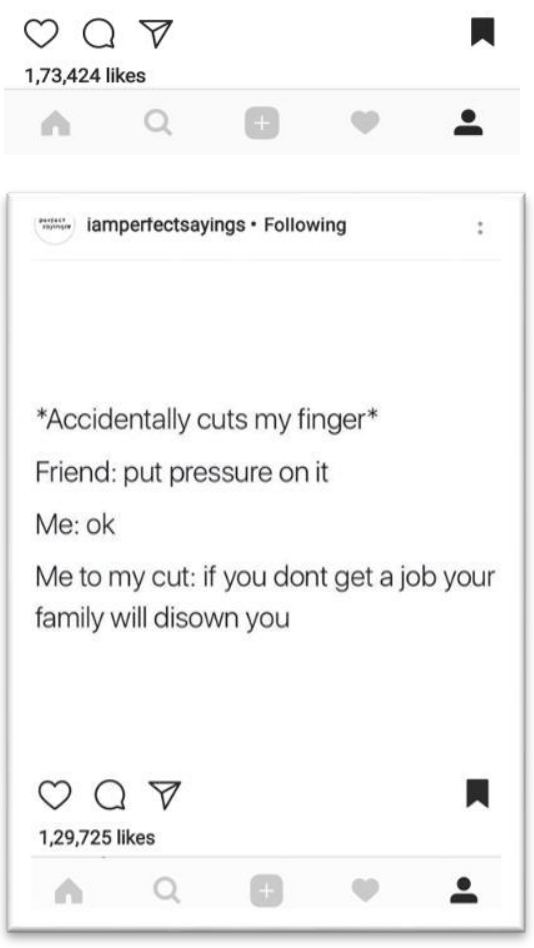

Fig.9: Examples of Instagram posts showing Short Conversations
Short Conversations: In some of the posts, short conversations or dialogues are used to convey some kind of message. Sometimes, they even entertain us with the humour created.

E.g. 'Society: Be yourself.

Society: Not like that.'This short conversation is enough to tell the hypocritical attitude of society and its relation with the human being.

More examples:

a) Brain: Be patient.Heart: Until when?

b) Nutritionist: A good calorie intake is $1200 \mathrm{a}$ day.

Me: Okay and how many at night?

c) People: You're gonna end up alone cus you're too picky.

Me: You all are gonna end up divorced cus you settle for less.

d) Boss: How good are you at PowerPoint?

Me: I Excel at it.

Boss: Was that a Microsoft Office pun?

Me: Word.

\section{CONCLUSION}

1) There are various factors responsible for variation in normal form of language used in posts on Instagram, which are - Oxymoron, Pun, Repetition, Wordplay, Metaphors, and Questions.

2) This variation in normal form of language can create special effects of emphasis, persuasion, emotional effect, etc.

3) The main reason for the popularity of posts is their brevity and catchiness. They have maximum effect on human mind in minimum words. The various forms or structures of representation of these posts are effective in this matter. E.g. short conversation, a dialogue, 3 lines-1 thought, 6 words story, etc.

4) The short nature of these posts makes them convenient for reading in this fast life of today. They can also be considered miniature forms of literature due to their brevity.

5) Overall, it can be said that these posts on social media are serving the purpose of 'brain food' or rather 'life food' in today's life in some or the other way to some extent. Still, they can not replace books in any way, but these posts can be considered to be an 'adjustment' in the current situation. 


\section{REFERENCES}

[1] Abrams, M.H. and Harpham, Geoffrey (2015). A Glossary of Literary Terms ( $11^{\text {th }}$ ed.). India: Cengage Learning India Private Limited

[2] Crystal, David. (2001).Language and the Internet. United Kingdom: Cambridge University Press

[3] Hunt, Andy. (2005). Your Research Project - How to manage it. Oxon: Routledge

[4] Moody, H.L.B. (1970). Varieties of English. London: Longman Group Limited

[5] Rozakis, Laurie. (2003). How To Interpret Poetry. Singapore: Thomson Asia Pte. Ltd. 